\title{
DISCURSO DE LA SRA. LUZ MARÍA REYES SANTELICES, DIRECTORA DE LA ESCUELA DE DERECHO DE LA UNIVERSIDAD CATÓLICA DEL NORTE EN CEREMONIA DE HONOR AL SESQUINCENTENARIO DE LA I. CORTE DE APELACIONES DE LA SERENA. 19 DE AGOSTO DE
} 1999

Nos cơngrega esta tarde, un motivo de especial significación. En los próximos días, el más alto tribunal de justicia de esta jurisdicción cumple 150 años, desde que fuera legalmente instalado en la ciudad de La Serena.

Una fecha como ésta nos invita a reflexionar en torno a la trascendencia de la tarea judicial, al deber fundamental de administrar justicia y principalmente sobre la justicia misma, virtud que se nos ha presentado a través de los siglos con la fisonomía recibida del pensamiento griego, de la teología biblica, del derecho romano y la filosofía escolástica.

Variados han sido los conceptos que sobre la justicia hemos recibido en nuestra época de estudiantes, fundamentalmente provenientes de la literatura griega clásica y de los fragmentos presocráticos, de Aristóteles, del antiguo y el nuevo testamento, de los libros bíblicos, de los juristas romanos, de Santo Tomás.

En suma, la justicia es una manera humana o divina de ser, que consiste en dar o hacer a otro lo que a este otro le corresponde por si mismo o incluso por una gratuita retribución.

Ante un acontecimiento tan importante de la I. Corte de Apelaciones de La Serena, hemos considerado de justicia rendirle un sentido homenaje en su sesquicentenario y reconocer publicamente la integridad y sabiduría de quienes desde su creación han hecho vida, día a día, esta virtud, con voluntad limpia y desinteresada, con abnegación, criterio y con responsabilidad compartida sobre el destino propio y el del otro, muchas veces bajo una inmerecida incomprensión de la sociedad.

Académicos, Profesores, Licenciados, Egresados y Alumnos de la Escuela de Derecho, deseamos expresar a la llustrísima Corte de Apelaciones de La Serena el respeto y la consideración por su docta y fructífera jurisprudencia, que ha constituido un significativo aporte a la paz social y al estado de derecho y un motivo de orgullo para quienes en esta jurisdicción hemos hecho del estudio del derecho la razón de nuestro afán profesional. Asimismo, nuestra comunidad universitaria ha querido brindarle su agradecimiento por el invaluable apoyo que ha otorgado a la Escuela de Derecho desde su creación y es por ello que han querido estar presentes en esta ceremonia el señor Rector 
de la Universidad Católica del Norte don Juan Music Tomicic y el Señor Vicerrector de sede don Renzo Follegati Ghio.

Recordar es volver a pasar algo por el corazón, traerlo de nuevo a la existencia en una perspectiva distinta.

Si intentáramos reconstruir la historia de la estrecha y decidida relación entre la Ilustrísima Corte de Apelaciones de la serena y la Escuela de Derecho de la Universidad Católica del Norte, que surge incluso antes del inicio de sus actividades académicas, podríamos señalar que quienes en primer término conocieron el proyecto de creación de la carrera, en 1992, fueron los que eran a la sazón ministros de este alto tribunal.

Como no recordar en estos momentos las conversaciones sostenidas con su entonces Presidente don Federico Pizarro Contador, y con los ministros don José Pavisic, doña Keryma Navia y don René Marín, y con quien era juez del segundo juzgado de letras de la serena, ministro don Alfredo Azancot.

Ellos, con la cautela propia de quienes son por excelencia guardianes del derecho y la justicia, manifestaron algunos su entusiasmo, otros su legítima inquietud e incertidumbre frente a lo que podría ser una Escuela de Derecho, en una región como la nuestra.

Pero todos a poco andar y ante la inminencia de la apertura de la carrera, en cumplimiento de la misión y el plan de desarrollo corporativo de nuestra casa de estudios superiores, y después de conocer a cabalidad nuestro proyecto académico, decidieron otorgarle su calificado apoyo.

Pero el sentido de una tarea de tanta envergadura requería algo más que un aporte inicial, ya que sabido es que, a solas, nadie, ni la institución más sólida ni la persona más dotada pueden realizar una actividad creadora.

Lo que otorga a nuestra vida sentido es la existencia del ser o los seres que nos ofrecen posilidades para vivir creativamente.

Nada importa que alrededor de una idea pululen millones de seres si al menos unos pocos no facilitan las posilidades para desarrollar un juego creador, al interior de la universidad.

Creatividad significa recibir activamente posibilidades fecundas en orden a dar origen a algo nuevo que encierra un valor. La creatividad es dual, dialogística, implica la apertura del sujeto creador a realidades que son diferentes de él y en principio distantes, externas, extrañas, ajenas, pero que pueden llegar a serle muy cercanas, sin dejar de ser distintas.

El encuentro producido entre la I. Corte de Apelaciones de La Serena y la Escuela de Derecho de la Universidad Católica del Norte, no es mera vecindad, fruto de la anulación de las distancias. Es sencilla y profundamente un entreveramiento de dos ámbitos, dos realidades que son centro de iniciativa en relación a la obligación de pro- 
mover el estudio y la reflexión en torno a los grandes temas del derecho. A las dos instituciones les correponde también la delicada misión de resguardar el prestigio de la profesión de abogado, que todos, magistrados y profesores de esta Escuela de Derecho, hemos jurado, en audiencia pública ante la Corte Suprema reunida en pleno, desempeñar leal y honradamente.

Al producirse este encuentro, a principios de 1993, percibimos la adopción de una serie de actitudes vinculadas entre sí, las que arrancan de la manifestación de generosidad de todos quienes integran en esa epoca la I. Corte de Apelaciones de La Serena: los Ministros Federico Pizarro Contador y José Pavisic Dragnic, y los Ministros suplentes Alfredo Azancot Vallejo y Miguel Vásquez Plaza, la secretaria María Angélica Schneider Salas y el Relator Diego Simpértigue Limare. Ellos concurren, el 11 de marzo de 1993, cuatro días antes del inicio de las clases correspondientes al primer año académico, hasta el Campus Miraflores de la Universidad, para suscribir junto a otras personalidades del mundo del Derecho, en presencia de todos los medios de comunicación de la región, un acta de constitución del Consejo asesor de la Dirección de la Escuela de Derecho, la que en su parte sustancial dice: "Los integrantes del Consejo asumen, en este acto, el compromiso de otorgar a la Dirección de la Escuela un permanente apoyo a través del intercambio de opiniones en torno al desarrollo de las actividades asumidas por ésta y asimismo, el de servir de vínculo, con los abogados de la zona, instándolos a contribuir al logro de un nivel universitario y cultural de la Escuela, de la más elevada excelencia".

Desde este compromiso inicial, hemos tenido, como Escuela de Derecho, el privilegio de disfrutar durante estos años, de las virtudes propias de esta capacidad de encuentro con la I. Corte de Apelaciones, como la apertura de espíritu, la disponibilidad, la veracidad, la voluntad de estar a la escucha, la simpatía, la fidelidad, la lealtad, la paciencia, la magnanimidad, la sencillez.

Así, la vida de nuestra escuela de derecho se desenvuelve en una armoniosa vinculación con la comunidad jurídica regional, la que en gran medida se logra gracias a la invaluable participación y aporte de quienes desempeñan sus importantes funciones en la Corte de Apelaciones.

Cada año, desde 1994, los hemos tenido en nuestras aulas universitarias.

Así, Miguel Vásquez y Diego Simpértigue dictan clases de Derecho Civil. Derecho Procesal y Práctica Forense, más adelante los ministros Juan Shertzer, Alfredo Azancot y Jorge Zepeda inician cursos de derecho procesal que mantienen hasta hoy, el fiscal Humberto Mondaca se incorpora a la docencia en Derecho Penal. Y también han integrado a fines de año comisiones examinadoras, lo que nos ha permitido tener una calificada evaluación de la docencia, los ministros José Pavisic, Isabella Ancarola y María Angélica Schneider, la fiscal Erica Noack, los relatores Cecilia Rojas, José María Toledo y Tomás Gray.

Cada año, desde 1994, hemos presentado la Revista de Derecho de la Escuela en la Sala de Alegatos de la Corte, de tanta tradición y prestigio en la administración de 
justicia, ante la presencia de magistrados abogados y estudiantes de Derecho, permitiendo en esas ocasiones su relación con las más altas autoridades de la Universidad Católica del Norte.

Así como en un canto polifónico todas las voces son distintas, independientes y autónomas y al mismo tiempo actuan en perfecta solidaridad dando vida a ese maravilloso fruto de la creatividad humana que es la armonía musical, así durante estos años, unidos, hemos venido resguardando el prestigio de la profesión de abogado y soñando un futuro promisorio para las nuevas generaciones de juristas, que con tanto esmero estamos formando jueces y abogados, en una comunión diaria de grandes y nobles ideales.

\section{Sus Señorias llustrísimas}

Por esta capacidad especial para colaborar en la configuración de una época verdaderamente posmoderna, caracterizada por un nuevo humanismo, el humanismo de la unidad y la solidaridad, por su generoso aporte y por transmitirnos su ideal de justicia, reciban en el sesquicentenario de la Corte de Apelaciones de La Serena, el reconocimiento, la gratitud y el aprecio de La Escuela de Derecho de la Universidad Católica del Norte. 